\title{
EDITORIAL \\ La velocidad de la Ciencia JuRídica: UNA ASIGNATURA PENDIENTE
}

jordi Delgado Castro*

Los procesos editoriales tienen su tiempo. Normalmente, las directrices que se entregan a los autores exponen procedimientos claros, ágiles y rápidos. Se trata de reglas que, del mismo modo que las reformas procesales, venden conceptos que, lamentablemente, no se condicen con lo que la realidad termina decretando.

Esta pequeña introducción a un nuevo volumen de lus et Praxis pretende explicar qué sucede en la cotidianeidad, entregando luces a quienes nos vemos sometidos a estas sinuosas sendas. En primer lugar, al ser recibido un original se somete a un filtro formal que cada vez es de mayor exigencia. Se deben cumplir las formas de preparación de los manuscritos independientemente de su calidad. Ello llevará un tiempo que, afortunadamente en Chile, cada vez será menor puesto que prácticamente todas las revistas indexadas hemos adoptado el mismo estándar. La comunidad científica está acostumbrada y en trabajos de otra índole como capítulos de libro o publicaciones de actas de jornadas o congresos, también se sigue. Principalmente, en este sentido, quienes suelen tener mayores reparos son los trabajos que provienen del extranjero, pues muchas veces están acostumbrados a otra forma de trabajar.

Una vez superado este primer nudo, se discute con el Comité Editorial-sobre la calidad aparente del manuscrito y sobre su correlación con el tipo editorial propuesto por el autor al subir su propuesta. Habitualmente, quien presenta un artículo científico suele acertar con su catalogación, sin embargo, a veces se trata más bien de un ensayo y hay que conversar con el autor su disposición a someterlo al procedimiento en esa lógica. Este peldaño en la cadena suele ser de fácil despacho y tiene una demora breve. Pero una dilación que sumada a lo que se narrará genera una moratoria total, absolutamente injustificable a los ojos de quien desea publicar un importante esfuerzo y, también, indeseada desde quienes conducimos este esfuerzo.

\footnotetext{
* Editor Revista lus et Praxis, Profesor de Derecho Procesal de la Facultad de Ciencias Jurídicas y Sociales de la Universidad de Talca. Correo: jdelgado@utalca.cl.
} 
Empieza, entonces, el momento más complejo del proceso: encontrar, al menos, dos árbitros idóneos. Para ello, también en permanente diálogo con el Comité Editorial, se trata de averiguar quién ha trabajado anteriormente ese mismo tema, o temas conexos. El acierto en la idoneidad del árbitro determinaría, teóricamente, una mejor evaluación, por lo que se trata de, probablemente, el instante de mayor complejidad y en el que se trata de aplicar el mejor brío. Sin embargo, la realidad nos conduce a una cadena de sucesos que evaporan del ambiente el que un manuscrito se presente y sea publicado en un espacio más razonable de tiempo.

El mundo científico académico es excesivamente pequeño. Los intentos por encontrar un par ciego idóneo se van diluyendo, pues los autores se conocen entre sí. La mayor parte de las veces vieron una ponencia del autor, participaron en un seminario de retroalimentación, evaluaron un proyecto del que trae origen la investigación, fueron árbitros para el original en otra revista... y, así, un elevadísimo número de razones que les impiden cumplir en forma ciega su cometido. Esto se trata del problema más complejo al que nos enfrentamos: encontrar un árbitro es fácil, pero localizar a uno que sea ciego resulta muchas veces una odisea. A ello, para sumar algo de descargo e inocencia en nuestro proceder, hay que adicionar el hecho de que los desinteresados e imprescindibles árbitros también cuentan con tiempos escasos que no les permiten dar comunicación tan fluida como quisieran a sus indicaciones para con lus et Praxis.

Teniendo a los árbitros comienzan los famosos veinte días hábiles para realizar el encargo. Una labor gratuita, desinteresada, concienzuda, poco valorada por las Universidades y que, en ese entendido, entran en un nivel de prioridad menor del que todos quisiéramos. Entonces, empiezan nuestros correos de recordatorio y nuestras súplicas lastimeras para que se completen las tareas. Un esfuerzo titánico que la comunidad científica en su conjunto hace y del que incluso con prórrogas y demoras, solo podemos agradecer.

Pero nunca (casi nunca en rigor) un artículo es perfecto, o no es perfectible cuando es evaluado por alguien idóneo. Adicionalmente, el paso de este breve tiempo suele destapar nuevos cambios jurisprudenciales, tendencias doctrinarias o estudios comparados que abordan temáticas conexas. Entonces, de los arbitrajes suelen llegar sugerencias que obligan al autor a hacer modificaciones, no siempre tan breves y que, seguramente, llegan en mal momento, pues los autores planificaron su año y se están dedicando a otras labores tan importantes como la redacción de un artículo científico.

Una vez recibida la versión mejorada se devuelve al arbitraje ciego que debe realizar una acción mucho más breve: observar si se acogieron satisfactoriamente las sugerencias y determinar si el artículo está en mejores condiciones y, por tanto, puede ser objeto de publicación. Algo tan, aparentemente, sencillo 
puede convertirse en especialmente difícil ya que, comprensiblemente, el evaluador ya hizo su tarea y esta revisión se torna tediosa y psicológicamente parece de menor entidad, con lo que todavía entra en una categoría más baja del escalafón de prioridades.

Como fuere, una vez aceptado, entra en cola de impresión. Quizá ya no sea el término más apropiado, pero eso es harina de otro costal. El volumen de trabajos que están en esa categoría torna todavía menos auspicioso el panorama. Ahora que el trabajo está formalmente aprobado debe esperar mucho, demasiado tiempo a que vea la luz. Es probable que pierda actualidad, que se vea rápidamente superado, que cambie la jurisprudencia, que otro trabajo vea sea publicado... y el autor ya no tiene nada más que hacer. Son muchos los casos en que hemos visto como un excelente trabajo perdía vigencia por lo desmedido que se ha vuelto este panorama.

Lo peor de todo es que este escenario es el más optimista, entre tanto, pueden suceder muchas cosas que van a ir atrasando cada vez más todo. Autores que envían nuevas versiones, revisores que no contestan, correcciones que no satisfacen, avalanchas de artículos que colapsan la cola de impresión... y tantas, cosas que, en definitiva, hacen que la velocidad de la ciencia pierda sentido. El más catastrófico de los escenarios es la divergencia entre las observaciones de dos árbitros: hay que buscar un tercero dirimente y ello va a significar una buena inversión de tiempo.

¿Qué hacemos para solucionar esto? Sin duda, siempre tratar de revisar los protocolos. No son muy complejos, pero siempre hay una idea que permite mejorar. Compartir experiencias con la comunidad científica; algo tan simple, como conversar con pares y pedirles que nos ayuden en la toma de conciencia del desarrollo de la noble labor de árbitro... Pero nunca alcanza para conseguir un estándar satisfactorio. En esta línea, entonces, se nos ocurrió tratar de descomprimir la cola de edición. Para ello, renunciamos al papel, nos concentramos en un modelo digital que permita mayor rapidez y, con mejores costos, mayor volumen. Entonces, en lo sucesivo lus et Praxis presentará tres números al año, aumentando significativamente el número de páginas por publicación. Es una medida que pretende mitigar, en parte, la lentitud. Seguramente no será la única, ni la mejor, pero esperamos poder contribuir a difundir los excelentes productos que recibimos, en forma más veloz.

Los dejamos, entonces, emplazados a juzgar esta nueva forma de trabajo y a colaborar como comunidad científica esperanzados por una mejor gestión. 
